\title{
DESAFIOS ÉTICOS E METODOLÓGICOS NA CRIAÇÃO DE FARMING GAMES
}

\author{
Adriana Falqueto Lemos (Ifes) ${ }^{1}$ \\ Bruno Gutierrez Ratto Clemente (Ifes) ${ }^{2}$ \\ Emmanoel Loss Dias (Ifes/Fapes) ${ }^{3}$ \\ João Nacir Colombo (Ifes) ${ }^{4}$
}

\section{RESUMO}

Este artigo visa a divulgar as discussões concernentes à execução da primeira etapa do projeto de pesquisa experimental "criação de farming game do campus Santa Teresa”, financiado pela Fundação de Amparo à Pesquisa e Inovação Tecnológica do Espírito Santo (Fapes), que objetiva a criação de um jogo que seja tanto atrativo quanto próximo do real. O texto inicia com uma revisão de literatura da área dos games studies, que nos permite adentrar as questões inerentes à multidisciplinaridade dos estudos nesse âmbito de pesquisa e a elaboração de debates sobre o que chamamos de "fíccionalização do real". Em segundo momento, analisam-se os jogos de gênero farming game, o que suscita discussões sobre como criar jogos desse gênero que sejam mais próximos da realidade. Essas discussões suscitam os desafios éticos e metodológicos aqui discutidos.

Palavras-chave: Games studies. Farming games. Olericultura. Ficção. Jogos Digitais.

\section{ETHICAL AND METHODOLOGICAL CHALLENGES IN THE CREATION OF FARMING GAMES}

\begin{abstract}
This paper aims to publicize the discussions concerning the execution of the first stage of the experimental research project "Santa Teresa campus farming game creation", funded by the Foundation for Research and Technological Innovation of Espírito Santo (Fapes), which aims to

\footnotetext{
${ }^{1}$ Mestre e Doutora (2018) em Letras pelo Programa de Pós-Graduação da UFES. Professora do Instituto Federal do Espírito Santo, campus Santa Teresa. E-mail: flemos@gmail.com

${ }^{2}$ Mestre em Informática pela UFES (2016). Professor do Instituto Federal do Espírito Santo, campus Santa Teresa. Email: brunoclemente88@gmail.com

${ }^{3}$ Mestre em biotecnologia pela UFES (2016). Graduando do curso de Análise e Desenvolvimento de Sistemas do Ifes, campus Santa Teresa. Bolsista da Fapes. E-mail: emmanoell@gmail.com

${ }^{4}$ Doutor em Fitotecnia pela Universidade Federal de Viçosa - MG (2013). Professor do Instituto Federal do Espírito Santo, campus Santa Teresa. E-mail: joaonacirc@yahoo.com.br
}

Manuscrito submetido em: 29/05 / 2018

Aceito para publicação em: 21 /11 / 2018

Revista Ifes Ciência, v.4, n.2, 2018 - Instituto Federal do Espírito Santo 
create a game that will be both attractive and close to the real. This paper begins with a review of the literature of the area of games studies, which allows us to penetrate the issues inherent to the multidisciplinarity of the studies in this scope of research and the elaboration of debates about what we call "fictionalization of the real". Secondly, we analyze the games of the genre farming game, which raises discussions about how to create games of this genre that are closer to reality. These discussions raise the ethical and methodological challenges discussed here.

Keywords: Games studies. Farming games. Olericulture. Fiction. Digital games. 


\section{INTRODUÇÃO}

Desenvolveremos o texto dessa introdução dividindo-o em duas partes: a primeira delas trás a justificativa da nossa pesquisa, que se ancora em dados de censos e pesquisas sobre a necessidade de ampliação de mão de obra num setor importante para a economia, que é a criação de games; na segunda etapa, veremos a revisão de literatura sobre o gênero de jogo digital que privilegiamos na pesquisa, o farming game. Essa revisão de literatura e a discussão que ela suscita são de extrema importância para que se possam compreender os desafios éticos e metodológicos que se apresentam face ao nosso objetivo, que é o de criar um jogo digital que seja mais próximo da realidade sem que se perca o fator de atratividade.

\section{O campus Santa Teresa em face da criação de jogos}

O campus Santa Teresa do Instituto Federal de Educação (Ifes) atende às demandas educacionais e profissionalizantes da comunidade onde está localizado desde sua criação, em 1941. A partir de 1946 até o momento, oferece ensino técnico na área agropecuária. Após se tornar um campus do Ifes, a ex-escola agrotécnica/agrícola passou a oferecer cursos de ensino superior, dentre eles, o curso Tecnólogo em Análise e Desenvolvimento de Sistemas. Temos, assim, dois campos científicos que convergem no campus Santa Teresa: o da ciência da computação e o da agronomia, e é parte da tarefa dos professores do instituto potencializar a capacidade científica do campus.

Tratando-se especificamente da computação, os jogos digitais têm potencial para gerar trabalho e renda; para tal, é preciso capacitação técnica e um trabalho multidisciplinar (FLEURY et al., 2014a, p. 53). Mas apesar da maioria das empresas desenvolvedoras de jogos estarem localizadas no Sudeste, o Espírito Santo mal aparece nas estatísticas, representando apenas 3,36\% do total de empresas (FLEURY et al., 2014b, p. 35). A maioria das empresas no Brasil ainda é classificada como pequena e está em seu estágio inicial (FLEURY et al., 2014b, p. 38). Mesmo assim, desde 2009, ressalta-se a importância de plataformas de desenvolvimento para mobiles como fator de impulsão do mercado de games. Das empresas, $81 \%$ desenvolvem seus jogos hoje para a plataforma Android (FLEURY et al., 2014, p. 50). O número de pessoas envolvidas na criação dos jogos ainda é pequeno, pois $44,4 \%$ das empresas participantes do censo são compostas por até 5 pessoas. A partir desses dados, nota-se que é importante que o estado do Espírito Santo amplie sua participação no mercado nacional de jogos. Para isso, é preciso que os centros de formação profissional e os professores promovam ações afirmativas para a aquisição de incentivos financeiros, bolsas, auxílios, e que organizem projetos que aglutinem a comunidade e as tecnologias de desenvolvimento de sistemas onde estão inseridas. No entanto, Alves (2010) aponta para o fato de que os cursos superiores que Revista Ifes Ciência, v.4, n.2, 2018 - Instituto Federal do Espírito Santo 
têm ligação direta ou indireta com o desenvolvimento de jogos ainda não têm estrutura suficiente para que, de forma autônoma, possam formar profissionais competentes. A ampliação do mercado de jogos ampliou o valor da multidisciplinaridade nessa seara (FRAGOSO et al., 2016).

A pesquisa em questão, "criação de farming game do campus Santa Teresa", visa a preencher as lacunas que se apresentam no Espírito Santo, ou seja, promover a formação de mão de obra capacitada com financiamento de bolsa, além de viabilizar um projeto integrado com corpo multidisciplinar. Partindo das premissas levantadas e privilegiando o atendimento das demandas e interesses da comunidade, decidiu-se eleger como ponto de partida a identidade do campus Santa Teresa do Ifes para a criação de um jogo. Como o campus é, em si, uma fazenda e atende majoritariamente à comunidade rural, seus cursos de matriz herdam a tradição da antiga escola agrotécnica.

\section{Os Farming Games e as questões éticas}

Dada a particularidade, o histórico e a cultura do campus Santa Teresa, favoreceu-se a análise, a princípio, dos chamados farming games. Nesses jogos digitais, chamados agriculture games ou mesmo farming games, o jogador deve manter uma pequena fazenda em funcionamento. Nos farming games, o design é formulado para que seja possível representar ludicamente os processos de trabalhos agrícolas e agropecuários da vida real.

Como ponto de partida para o desenvolvimento da pesquisa "criação de farming game do campus Santa Teresa”, analisamos os dados oriundos do projeto de Iniciação Científica Jr. "Representações agropecuárias e agriculturais em jogos digitais" (2017) ${ }^{5}$, cujo objetivo era desenvolver leituras críticas sobre as representações de práticas agriculturais e agropecuárias em cinco jogos do gênero farming games: Hay Day (2013), da Supercell; Township - Fazenda e Cidade (2017), da Playrix Games; Top Farm (2017), da MPForce; Let's Farm (2017), da Playday Games; e Farm Story 2: Jogos de Fazenda (2017), da Storm8 Studios.

Observou-se a partir das análises deste projeto de Iniciação Científica Jr., preponderantemente, o distanciamento do que se pode entender como uma realidade sensível do mundo agrícola e do campo dos mecanismos representados nos jogos em questão; ou seja, é como se esses jogos fossem uma fantasia, longe de serem produções inspiradas no trabalho agropecuário. A

5 Apesar da pesquisa desenvolvida nesse âmbito não ter sido publicada ainda, ela ocasionou a produção de um artigo intitulado "Representações agrícolas e agropecuárias em Farming Games" que está no prelo, além dos relatórios da pesquisa enviados via sistema Sigpesq do Ifes.

Revista Ifes Ciência, v.4, n.2, 2018 - Instituto Federal do Espírito Santo 
abstração da realidade é perturbadoramente higienizada e simplificada. Um dos pontos de crítica mais intensos foi o da representação do tempo, coadunando, por exemplo, com a fala atentada de Chang (2012), ao dizer que "em FarmVille, o trabalho que normalmente leva temporadas inteiras para se concretizar, que no mundo físico é vulnerável a todos os tipos de reduções naturais, é condensado no trabalho fácil de alguns minutos e horas" 67 (2012, p. 5).

Concordamos com a autora no que diz respeito à simplificação dos processos do campo, já que

\begin{abstract}
O apagamento tecnológico promovido pelos jogos agrícolas no que diz respeito ao trabalho humano, animal e ambiental, em muitos aspectos, simplesmente estende as noções pastoris convencionais da vida no campo, que tendem a obscurecer o trabalho ali envolvido, imaginando a vida rural como algo de alguma forma tanto produtivo quanto ocioso. Raymond Williams, em $O$ país e a Cidade, traça um panorama genealógico particularmente perceptivo do gênero rural e sua predicação, em uma desatenção estudada aos desconfortos e deslocamentos da classe trabalhadora ${ }^{8}$ (CHANG, 2012, p. 5).
\end{abstract}

De acordo com a leitura de Chang e com os resultados evidenciados pelo relatório de Iniciação Científica Jr., compreende-se que os farming games promovem uma visão do mundo rural que é no mínimo enganosa, já que propagandeia uma visão romântica e que ignora a realidade desse setor de produção. Na verdade, de acordo com Chang,

[...] assim como os jogos agrícolas negligenciam as realidades politicamente impalatáveis dos trabalhadores agrícolas explorados e historicamente excluídos, eles também fecham os olhos para o trabalho não-humano e as realidades ecológicas igualmente desagradáveis de resíduos industriais, entropia e limitação de $\operatorname{recursos}^{9}(2012$, p. 8).

Oferecendo uma abstração da realidade, os farming games são tão artificiais, segundo Chang, quanto a própria noção perpetuada pela cadeia de mercado na qual vivemos.

Jogos de fazenda oferecem paraísos bucólicos onde o uso de máquinas e métodos agrícolas intensivos nunca leva à degradação ambiental, onde os animais podem ser usados como produtos sem sofrerem danos visíveis, e onde recursos naturais essenciais como água limpa e solo rico em nutrientes estão sempre disponíveis, nunca sujeitos à competição. Juntamente

6 Todas as traduções são de nossa autoria, salvo se expressas nas referências.

$7 \quad$ "In FarmVille, work that typically takes entire seasons to come to fruition, that in the physical world is vulnerable to all sorts of natural reductions, is condensed into the easy work of a few minutes and hours" (CHANG, 2018, p. 5).

8 "Farm games' technological effacement of human, animal, and environmental labor in many ways simply extends conventional pastoral notions of country life, which tended to obscure labor by imagining rural living as somehow both productive and idle. Raymond Williams, in The Country and the City, offers a particularly perceptive genealogical tracing of the pastoral genre, and its predication on a studied inattention to the discomforts and dislocations of the laboring class" (CHANG, 2012, p. 5).

9 "[...] just as farm games overlook the politically unpalatable realities of exploited and historically excluded agricultural workers, they also turn a blind eye to nonhuman labor and the equally unpalatable ecological realities of industrial waste, entropy, and resource limitation" (CHANG, 2012, p. 8).

Revista Ifes Ciência, v.4, n.2, 2018 - Instituto Federal do Espírito Santo 
com o inevitável esgotamento do solo e outros recursos, os jogos agrícolas também ignoram as restrições típicas do clima, estação do ano e temperatura, excluindo-os da instanciação no jogo e incentivando o uso inteligente de soluções técnicas, variando do plausível, como estufas e fertilizantes químicos, para o fantástico, como o infame spray de "desmurchar" em FarmVille $^{10}$ (CHANG, 2012, p. 9).

Grande parte das inverdades representadas por esse tipo de jogo está, segundo Chang, na proposição de que o solo e a água (ricos, puros, férteis) estão à disposição e nunca sofrem degradação. A água desses jogos, segundo Chang (2012, p. 10), não tem custo e está sempre disponível, quase como um item decorativo. Apesar de ser representado como um item de valor indispensável, no nível de abstração, a água pode ser "plantada" em qualquer espaço com apenas um clique.

Jogos de fazenda não refletem a realidade da agricultura e pecuária, tendendo a ignorar fatores econômicos, ambientais, sociais e culturais que seriam importantes para que a representação dessa realidade não se tornasse tão omissa. Essa falta de fidelidade acaba causando uma falsa impressão para o usuário, o que resulta na má educação do mesmo. Fenômenos como chuva, tempo, custo de produção, clima, época, tratamento do solo, fatores ambientais, entre outros, não são levados em conta. Esse modelo sustenta a ideia da mecânica por trás do jogo casual, na qual o foco é a distração e a sedução do usuário. Uma "problematização" 11 dos processos envolvidos na produção do campo poderia refletir na produção de um novo sistema de representação do campo em farming games.

Parte-se, então, da proposição de que jogos digitais são ferramentas criadas para proporcionar lazer e são simulacros, ou simulações, de situações que podem ser reais ou fantásticas. Como jogos são simplificações e simulações (CRAWFORD, 2000), eles projetam representações dessas atividades, ou seja, eles fazem uma transposição do real para a ficção.

Jogos também são ferramentas éticas, morais e políticas (SICART, 2011; BOGOST, 2008), portanto, as representações presentes neles viabilizam certas visões de mundo que, naturalmente, calam outras. O que se vê são jogos nos quais, por exemplo, a agricultura parece uma atividade de lazer e as plantações crescem sem insumos e sem a influência do tempo. Isso cria falsas impressões, como a de que não é preciso mais do que água para gerir uma plantação ou para cuidar de animais.

10 "Farm games offer bucolic paradises where the use of machinery and intensive agricultural methods never leads to environmental degradation, where animals may be harvested for products without coming to noticeable harm, and where key natural resources like clean water and nutrient-rich soil are always available and never subject to competition. Along with the inevitable depletion of soil and other resources, farm games also bypass the typical restrictions of climate, season, and weather, both by excluding them from instantiation in the game and encouraging the clever use of technical solutions, ranging from the plausible, such as greenhouses and chemical fertilizers, to the fantastical, such as the infamous "unwither" spray in FarmVille" (CHANG, 2012, p. 9).

11 As aspas indicam que o que a proposta de intensificar as representações não é apenas uma questão de se discutir a realidade, mas de tentar mostrá-la de forma mais viável.

Revista Ifes Ciência, v.4, n.2, 2018 - Instituto Federal do Espírito Santo 
Por conta das reflexões acima, resgatamos o trabalho do historiador cultural Roger Chartier, que em A História Cultural - entre práticas e representações (2002) estuda a forma como a cultura humana se propaga ao longo dos tempos. Para o estudioso, as produções culturais imiscuem a experiência coletiva e o sistema simbólico, incorporando e provocando práticas e representações que fazem parte da coletividade, de maneira circular.

\begin{abstract}
A problemática do "mundo como representação", moldado através das séries de discursos que o apreendem e o estruturam, conduz obrigatoriamente a uma reflexão sobre o modo como uma figuração desse tipo pode ser apropriada pelos leitores dos textos (ou das imagens) que dão a ver e a pensar o real (CHARTIER, 2002, p. 23-24).
\end{abstract}

Por esse ponto de vista, as representações trazidas por produções culturais (seja de livros, imagens, filmes, etc) são discursos que estruturam nossas vivências, e é preciso refletir sobre o que elas nos dizem. Nossos estudos sobre os jogos digitais se estruturam tanto nos games studies, campo científico específico, quanto nos estudos multi e transdisciplinares - compreendendo que cada campo de saber representado num jogo digital tem papel importante tanto na elaboração quanto na crítica do mesmo. Nesse caso, a crítica de jogos digitais pode ser empreendida através dos estudos da leitura de jogos e de suas representações - na aquiescência de que, ao termos contato com jogos, fazemos deles uma leitura que é uma abstração hermenêutica de seu conteúdo sincrético (texto, imagem, som, interface de interação física). Tendo a História Cultural como base, compreendemos o videogame tanto como objeto que merece um olhar específico (no tocante à análise de sua materialidade como um todo) quanto como um objeto em evolução no qual incidem avanços tecnológicos pelos quais passam e passaram mídias de transmissão de informação, de linguagem e de texto. Os jogos digitais, como objetos que materializam um texto, uma mensagem (portanto uma ideologia), fazem parte de uma série de outros objetos culturais que transmitem mensagens e que foram tecnologicamente aprimorados - desde meios mais rudimentares de transmissão de dados e ideias até aqueles providos de camadas de sentido (sincréticos/policódices), como o filme e o videogame (GALEY, et al., 2011, p. 39; PAIVA, 2006; BIGNOTTO, 1998). Já que os videogames são "jogos através da ficção" (TAVINOR, 2009, p. 30), partimos dos Estudos Literários para nos apropriarmos dos estudos das representações nos jogos digitais.

Partindo-se de toda a discussão trazida nesta introdução, surge como problema de pesquisa a questão: É possível criar um jogo para celulares que seja atrativo e que, ao mesmo tempo, represente a vida e o trabalho no campo de forma menos ficcional e mais próxima do real? São questões que esbarram tanto em discussões que imiscuem temas éticos quanto metodológicos. 


\section{METODOLOGIA}

Elaborou-se, a partir disso, uma metodologia que envolve uma revisão bibliográfica que favorece tanto uma importante discussão do aparato teórico ao qual se lastreia esta pesquisa (e aos quais se filiam seus pesquisadores), quanto às etapas e procedimentos envolvidos na elaboração do plano de ação para a implementação do jogo. Desenvolvemos uma revisão de bibliografia dos games studies privilegiando alguns teóricos que oferecem importantes discussões sobre de representações ficcionais em jogos (CRAWFORD, 2010; SICART, 2011; BOGOST, 2008; TAVINOR, 2009, CHANG, 2012), quanto da história cultural (CHARTIER, 2002; PAIVA, 2006; BIGNOTTO, 1998). Discutiram-se, também, questões próprias do universo físico a ser representado, no tocante a que tipo de aspecto da vida rural haver-se-ia tomar como tema do jogo, além das questões que estas escolhas implicariam na metodologia do trabalho de programação.

\section{RESULTADOS E DISCUSSÃO}

Tendo discutido de maneira breve nossa base teórica a respeito do que entendemos por representação e dinâmicas que se dão a partir dessa abordagem nos estudos críticos de jogos digitais, passaremos à discussão que se desenvolve diante do nosso objeto de pesquisa: um jogo de farming game que consiga se aproximar do mundo "real", de forma que implique questões éticas importantes no tocante aos cuidados com o solo, com a água, com o plantio, etc. - e como esses dados impactariam na constituição do jogo e na metodologia do trabalho a ser realizado na programação dos dados. Nesta sessão, traremos as discussões que resultam da revisão de bibliografia e que desaguaram nas soluções metodológicas que foram encontradas. Essas soluções visam a construção de um design de jogo que possa representar aspectos éticos e dinâmicos que concernem às práticas da vida no campo da forma mais aproximada o possível - no sentido de que o jogador entenda que o sucesso das colheitas tão é automatizado, que depende de conhecimento, dedicação e ciência.

\section{A olericultura e representações possíveis}

Por causa disso, a discussão sobre que tipo de produção rural seria escolhido para ser representado em jogo foi bastante importante. Optou-se pela olericultura, que é a parte da horticultura que trata da exploração de hortaliças. São consideradas hortaliças os vegetais que apresentam produção intensiva, elevada demanda por mão-de-obra, ciclo curto e áreas de cultivos de pequeno porte. As hortaliças são classificadas como frutos, herbáceas (folhosas, talos ou hastes e flores ou inflorescência) e tuberosas (tubérculos, rizomas, bulbos e tuberosas) (FILGUEIRA, 2008). 
No Brasil são cultivadas mais de cem espécies de hortaliças, sendo que no ano de 2016 foram produzidos quatorze milhões de toneladas, totalizando R \$33,3 bilhões (MELLO, 2018). Destacamse a batata (Solanum tuberosum), o tomate (Solanum licopersicon), o alho (Allium sativum) e a cebola (Allium cepa). As regiões sudeste e sul são responsáveis pela produção de $62,5 \%$ das hortaliças colhidas no Brasil (MELLO, 2018).

No Espírito Santo, a produção concentra-se na região serrana, destacando-se o município de Santa Maria de Jetibá. No mês de março, no CEASA-ES, foram comercializados 10,8 milhões de quilos de hortaliças (raiz, bulbo, tubérculo e rizoma), num total de 2,4 milhões de quilos de hortaliças folhas (CEASA-ES, 2018).

Além da importância econômica, vale destacar também a importância nutricional das hortaliças. Neste sentido, cabe destacar, por exemplo, as hortaliças ricas em carboidratos: batata (Solanum tuberosum), batata-doce (Ipomoea batatas) e taro (Colocasia esculentum). Há também as ricas em proteína: feijão-vagem (Phaseolus vulgaris) e ervilha (Pisum sativum). As couves (Brassica spp) e repolho (Brassica oleracea var. Capitata) são vegetais ricos em sais minerais. Já cenoura (Daucus carota) e abóbora (Cucurbita moschata) são ricas em vitamina A. A rica em vitamina B é o quiabo (Abemoschus esculentum).

Apesar disso, o consumo de hortaliças no Brasil é muito pequeno. Segundo Mello et al. (2018), um brasileiro consome em média $27,1 \mathrm{~kg}$ de hortaliças por ano, enquanto que em Israel são 73 kg, nos Estados Unidos são 98,5 kg e na Itália são 157,7kg. O uso do jogo poderá servir, além da importância anteriormente ressaltada, de incentivo para o aumento do consumo de hortaliças por parte da população, proporcionando uma alimentação mais equilibrada e saudável, além de aumentar a renda de agricultores familiares e gerar empregos devido à quantidade de mão de obra necessária.

Além disso, caso se crie um farming game mais realista, esse poderá prover ao agricultor informações técnicas necessárias de forma que este possa aumentar o nível tecnológico na exploração de hortaliças, alcançando maiores produtividades com sustentabilidade. Na zona urbana isso também será possível, visto que as informações trazidas pelo jogo podem ajudar a população em geral a também praticar o cultivo das hortaliças em quintais, ou mesmo dentro de residências, no que se denomina atualmente por "agricultura urbana".

A agricultura urbana (AU) é definida por Silva e Castanho (2011) como sendo toda prática típica do meio rural que ocorre no espaço urbano. Sendo assim, desde os primeiros indícios de cidades, havia espaços destinados ao cultivo, mesmo que em menor escala que o meio rural. Potencializada pelo uso de ferramentas, técnicas, maquinários e insumos, a utilização dos solos da 
agricultura cresceu, resultando em maior produtividade em menor espaço. Portanto, o jogo pode fomentar a população a se engajar em práticas de AU que sejam viáveis mesmo em pequenos terrenos nos quintais de suas casas ou em vasos dentro de casa.

A partir das noções acima estabelecidas elencamos uma lista de cinquenta e nove hortaliças que podem ser produzidas no Brasil, algumas delas muito populares, outras pouco conhecidas. Disponibilizar essa grande quantidade de hortaliças ao jogador pode parecer um desafio para o desenvolvimento do jogo ou da manutenção de sua simplicidade (em favorecimento do apelo ao jogador, que terá maior sensação de liberdade de escolha). Porém, objetiva-se que o jogador: a) possa compreender toda uma gama de produção que não necessariamente é popular, mas que existe; b) possa entender que o processo de escolha do que plantar na propriedade rural envolve fatores múltiplos, como custo de produção, comercialização, exigências climáticas, preferência do consumidor, exigência nutricional, resistência a problemas fitossanitários, exigência de água, etc.; c) possa tomar decisões sobre o que plantar, sem se restringir a poucos tipos de hortaliças; e d) seja capaz de compreender o efeito que uma grande quantidade de escolhas pode proporcionar, evidenciando as dificuldades nas tomadas de decisão que dizem respeito a toda uma série de cuidados que há de se ter na produção.

Dessa lista de cinquenta e nove hortaliças, elaborou-se uma tabela com vinte variáveis envolvidas no processo de cultivo. Essas informações, que envolvem, por exemplo, o espaçamento entre as hortaliças, temperatura adequada, época de plantio, tempo de germinação, etc., implicaram discussões e tomadas de decisões que evidenciaram como as questões éticas e estéticas se convergem no design de jogos digitais.

Observemos, por exemplo, a questão do espaçamento. O espaçamento é um fator muito importante para planejar o plantio de hortaliças. A partir dessa escolha haverá maior ou menor penetração de luz no cultivo, afetando diretamente a taxa fotossintética das plantas, o que por sua vez afeta a produtividade. Além disso, o espaçamento poderá influenciar na ocorrência de problemas fitossanitários, na competição por água e nutrientes entre as plantas, no deslocamento e interação dos trabalhadores rurais, entre outros.

\section{Discussões sobre o solo, irrigação e clima}

Ao discutirmos como desenharemos essa variável no jogo, observamos que é possível fugir aos preceitos mais comumente utilizados para a proposição de uma metodologia mais crítica. Se, ao arrastar a semente para o solo, o jogador visualizar o espaçamento adequado para o plantio, como Revista Ifes Ciência, v.4, n.2, 2018 - Instituto Federal do Espírito Santo 
uma sombra, ele não terá a oportunidade de compreender a importância dessa variável e porque esse é um conhecimento técnico relevante. Concordamos, portanto, que o jogador não deve ter acesso antecipado ao mapeamento ideal de espaçamento, mas que deve, às custas de erros e acertos, entender que existe uma distância ideal para o cultivo das hortaliças e que o conhecimento técnico adquirido nos cursos presentes no campus Santa Teresa também o auxiliará no jogo, assim como na vida. O jogador sem esses conhecimentos terá maiores dificuldades do que o aluno que já fez o curso Técnico de Agropecuária, por exemplo. O jogador deverá construir uma base de conhecimento sensível durante o jogo, que lhe servirá de base para as suas próprias ações a partir dos sucessos e fracassos ocasionados pelas suas escolhas de, por exemplo, espaçamento de plantio das sementes ou das mudas.

Há, na propagação e implantação das hortaliças, as formas sexuada e assexuada. Na propagação sexuada são utilizadas sementes botânicas, enquanto pela via assexuada, órgãos vegetativos das plantas. Assim sendo, para a implantação da batata-doce, utilizam-se ramas; no taro, rizomas; na batata, tubérculos; no alho, bulbilho e na couve folha, brotações axilares. Para que o design do jogo possa representar esse dado de forma adequada, é preciso diferenciar o processo de preparo do material propagativo, ou seja, ele não poderá simplesmente comprar uma semente de batata doce, já que elas só podem ser propagadas pela via assexuada. Assim sendo, é possível que se adote um sistema em que o jogador possa adquirir dinheiro e compre uma rama de batata doce ou que ele possa ter acesso a outros personagens dos quais possa comprá-la, sem que se comprometa a qualidade da representação e do jogo.

Adotaremos o solo do entorno do campus Santa Teresa, nas localidades de Santo Antônio do Patrimônio e São Roque do Canaã, e essa escolha se motiva justamente pelo fato de que este é um jogo de farming game do campus - então é preciso representar as condições climáticas do entorno. O local apresenta altitude de 160 metros, latitude de $19^{\circ} 48^{\prime}$ sul e longitude $40^{\circ} 40^{\prime}$ oeste. O solo é classificado como "argissolo" e a precipitação pluviométrica é de aproximadamente 1000 milímetros por ano. $\mathrm{O}$ clima é predominantemente seco e quente, com temperaturas chegando a $37^{\circ} \mathrm{C}$ no verão.

Para que se possa representar de maneira mais adequada a realidade local e para que o jogador possa compreender as dinâmicas envolvidas nos processos de cultivos dessas localidades, utilizaremos os dados meteorológicos, pluviométricos e geomorfológicos de fontes de dados como o sítio virtual do Instituto Nacional de Pesquisas Espaciais (INPE).

O site em questão dispõe de um web service de previsão do tempo com base em arquivos Extensible Markup Language (XML) que serão utilizados para que o jogador possa ter dados e planeje suas ações a partir de informações como temperatura, umidade, direção do vento, condições do clima, entre outros. Esses dados da cidade de Santa Teresa possibilitarão uma representação fiel do leque de Revista Ifes Ciência, v.4, n.2, 2018 - Instituto Federal do Espírito Santo 
condições climáticas encontradas na região, assim como as vantagens e desvantagens que possam representar no processo de cultivo de hortaliças.

O mesmo comportamento ocorrerá com o solo: Santa Teresa e região possuem uma variedade de solos e suas respectivas propriedades. Quando um jogador iniciar o jogo, ele receberá um terreno cujas propriedades serão aleatórias, mas que, ao mesmo tempo, simulem as propriedades de um dos tipos de solo que representem a região.

É possível que a variável de maior impacto no processo de desenvolvimento do jogo seja o tempo. Tanto no que tange ao tempo necessário para o desenvolvimento na produção de hortaliças, quanto na proporcionalidade entre as produções, o tempo em jogos de farming games é um parâmetro de impacto primordial.

\section{Discussões sobre a variável tempo}

Para lidar com tal variável, optou-se por manter o tempo do jogo em proporção exata à da realidade: a passagem de tempo ocorre em tempo real. Assim como a passagem do tempo, todos os fatores influenciados por esta variável também serão mantidos com a mesma proporção do mundo real: o tempo de uma hortaliça crescer, a duração de uma chuva ou a passagem das estações, por exemplo. Entretanto, essa abordagem pode facilmente se tornar uma experiência cansativa e desmotivadora para o jogador. Como solução, optou-se por uma barra de controle temporal que estará sempre presente na interface gráfica do jogo, possibilitando ao jogador acelerar (ou retardar) a passagem do tempo. Com isso ele poderá acelerar o tempo (para não esperar o tempo real de desenvolvimento da hortaliça) ou retardá-lo (para permitir melhor gerenciamento das tarefas a serem executadas na fazenda). A ideia é que se possa, dessa maneira, representar o tempo de forma um pouco mais equiparável com a realidade.

Em sua maioria, os jogos de plataforma frequentemente ignoram a passagem do tempo ou reduzem esse conceito em poucos elementos. Alguns jogos possuem apenas um relógio, que não produz alterações na mecânica do jogo. Outros jogos, como, por exemplo, jogos de corrida e esporte, controlam apenas dia e noite, o que não provoca nenhuma mudança além do efeito cosmético (substituição da luz solar pelo céu estrelado). Certos jogos, como Castlevania e Zelda: Ocarina of Time, possuem algumas mudanças de jogabilidade, como personagens, objetos ou evento que só aparecem em certos momentos do dia. Outros, como Baldur's Gate, The Sims e outros jogos de RPG, possuem um relógio fixo que só é alterado caso o jogador opte por fazer alguma atividade que consuma tempo, o que avançará esse relógio de forma pré-determinada. Conceitualmente é Revista Ifes Ciência, v.4, n.2, 2018 - Instituto Federal do Espírito Santo 
importante notar que nenhuma dessas implementações faz jus às influências que o tempo exerce sobre o plantio e a colheita.

\section{Mão-de-obra e qualidade da produção}

Outro fator frequentemente ignorado pelos desenvolvedores de jogos desse tipo é a necessidade de mão de obra ativa na fazenda. Da forma como são desenvolvidos, os jogos dão a entender que basta plantar uma semente no solo e aguardar até que ela esteja pronta - após um período definido de tempo. Na realidade, é necessário que seres humanos frequentem o local do plantio, reguem (automática ou manualmente), e que façam a colheita e transporte das hortaliças.

O mesmo vale para a qualidade do produto. A produção de jogos de farming games é feita de produtos que sempre possuem características exatamente iguais e com igual valor de mercado, ou seja, não há variedade na qualidade da produção.

\section{ALGUMAS CONSIDERAÇÕES}

Para entendermos como poderemos buscar alternativas para a representação do tempo, recorremos a algumas teorias da área de game studies, neste caso, a ideia de gamificação. Para Fardo,

\footnotetext{
A gamificação é definida como o processo de utilizar o pensamento e as mecânicas dos games para envolver pessoas, motivar a ação, promover a aprendizagem e resolver problemas. Para fazer uso da gamificação, deve-se pensar nela como uma caixa de ferramentas, onde estão dispostos os elementos dos games, usando estratégias, métodos e pensamentos para resolver problemas nos mundos virtuais em situações do mundo real (FARDO, 2013).
}

Ou seja, gamificar é o ato de tornar a realidade jogável, representável. Ao pensarmos nas questões temporais e de como representaremos o tempo, estamos, na verdade, ficcionalizando o real (dentro da compreensão de que os jogos são ficções, construções que funcionam como um simulacro da realidade, ou uma simulação - que, em todos ambos os casos, são ficções). O universo ficcional do jogo tem duas faces: uma delas, diegética - ficção dentro do próprio universo do jogo, o próprio universo ficcional, no tempo imaginado, com os personagens, etc. A outra face desse mundo é o nãodiegético - o mundo real. Ocorre que essas duas realidades se sincronizam em dado momento, já que o mundo diegético dos farming games só pode existir tendo como modelo o mundo não-diegético. Nesse sentido, gamificar, ou seja, transformar os processos do mundo físico agropecuário em procedimentos jogáveis (com atribuição de regras e valores) é uma tarefa de ficcionalização do real. 
As decisões por essa ou aquela apropriação do real para posterior representação através do projeto do jogo são motivadas por fatores intrínsecos a filiações de caráter ideológico daqueles envolvidos no design. Essas decisões sobre o que representar da vida rural tendem a super-simplificar a realidade do campo e não fazem jus ao esforço e empenho colocados em cada uma dessas atividades que fazem parte do processo, mas que não fazem parte do jogo. Sem todas as variáveis envolvidas nos processos de plantio e colheita, cria-se uma experiência que favorece a jogabilidade e não a realidade. Com as alterações necessárias, pode-se desenvolver um jogo que mantenha critérios importantes de jogabilidade sem perder a coerência e o respeito à realidade vivida pelas pessoas que trabalham no plantio e na colheita. Portanto, a busca pelo aprimoramento das técnicas de cultivo de olericultura será o verdadeiro desafio do jogador do Farming Game de Santa Teresa: trata-se de um processo contínuo de aprendizado.

O que nos move a decidir que o jogador não deve saber todas as informações sobre como cultivar as hortaliças a priori é a motivação por compreender que a educação formal do campo ofertada por cursos técnicos ou superiores é de alta importância para o fomento do setor agropecuário. Dessa maneira, preferimos que as informações sobre os cultivos das diferentes hortaliças possam ser acessados à medida que o jogador evolui no jogo, seja capitalizando e podendo pagar por apostilas e cursos, ou buscando informações com um professor especialista. Por mais simples que possam parecer, decisões sobre como representar ou ficcionalizar fenômenos reais não se dissociam da forma como enxergamos o mundo.

Para Alves (2010), faltam profissionais tecnicamente qualificados para o desenvolvimento de jogos em áreas como 3DMAX, Maia, Photoshop, Illustrator, dentre outros. Para Calomeno e Grimm (2010), os jogos que estão sendo desenvolvidos serão mais bem recebidos pela audiência se houver participação de outros profissionais no processo de criação. Cabe a esses outros profissionais, que não pertencem ao corpo tecnológico, atentar-se a outros recursos utilizados nos jogos, como a linguagem e o enredo. Assim sendo, percebe-se que as discussões envolvidas no projeto de design do jogo de "Fazendinha do Campus Santa Teresa" só podem se dar de forma efetiva e verticalizada se visar a responder à pergunta "É possível criar um jogo para celulares que seja atrativo, mas que, ao mesmo tempo, represente a vida e o trabalho no campo de forma menos ficcional e mais próxima do real?" com a participação de pesquisadores especializados nas áreas de conhecimento das informações que serão ficcionalizadas, gamificadas. A multidisciplinaridade é fundamental para que novos modelos de representação em jogos possam emergir. A própria área dos games studies é multidimensional (MURRAY, 2005, p. 2), portanto composta por agentes das mais variadas expertises. Contemporaneamente, estudiosos como Thomas Apperley e Darshana Jayemane (2017) 
procuram entender a etnologia das práticas que circulam através das estruturas de jogos digitais, como a formação das comunidades online, a prática física do contato com a infraestrutura desses objetos físicos e estudos e críticas do trabalho digital. À medida que os estudos avançam, as críticas de jogos se tornam multidisciplinares, fazendo com que os estudiosos trabalhem em grupo. Para além das questões técnicas aqui abordadas, além disso, observou-se a problemática da questão: é preciso que se sopesem questões éticas imbricadas no que se deseja representar como a vida do campo, porque a simplificação de práticas desse setor produz visões estreitas e por demais empobrecidas do trabalho feito no campo. A crítica e estudo dos processos de design e materialização de universos ficcionais (representacionais ou não) de jogos digitais carecem de atenção no que tange às questões inerentemente ideológicas, políticas, econômicas e sociais.

Repensar que tipo de representações e simplificações pode ser produzido remete-nos a refletir que se pode enriquecer o conhecimento que a sociedade tem da olericultura. Dessa forma, também se espera valorizar o trabalho de todos os homens e mulheres que vivem no campo e que, com sua dedicação e técnica, colocam nos nossos pratos fartura e saúde.

\section{AGRADECIMENTOS}

Agradecemos a Fundação de Amparo à Pesquisa e Inovação Tecnológica do Espírito Santo (Fapes) pelo apoio à pesquisa ora aqui apresentada, aprovada no Edital Universal 03/2017 intitulado “Jogo de Fazendinha do Campus Santa Teresa".

Agradecemos o trabalho de análise e pesquisa dos alunos bolsistas no projeto de Iniciação Científica Jr., do Edital 04/2017, intitulado "Representações agropecuárias e agriculturais em jogos digitais" do Instituto Federal do Espírito Santo (Ifes) do campus Santa Teresa: Daniel de Souza Lima, Douglas Stein Sabino, Igor Nunes Passos, Lara Lany Gomes Lyrio, Lorraine Karoline Oliveira Lopes e Victória Martineli de Souza.

Agradecemos o Ifes pelo fomento da pesquisa de Iniciação Científica "Representações agropecuárias e agriculturais em jogos digitais".

Agradecemos o campus Santa Teresa, em especial a Coordenação de Ensino, Pesquisa e Extensão e à Direção Geral do campus, pela disponibilização do espaço e dos recursos para realização da pesquisa.

Agradecemos a leitura atenta e sugestões feitas pelos pareceristas da revista Ifes Ciência. Trata-se de um artigo extenso e feito a muitas mãos; sem a leitura atenta e as críticas feitas não teríamos uma exposição tão clara da pesquisa como a que apresenta hoje. 


\section{REFERÊNCIAS}

ALVES, L.R.G. Games: desenvolvimento e pesquisa no Brasil. In: Nascimento, Antonio Dias; Hetkowski, Tânia Maria. (Org.). Educação e contemporaneidade: pesquisas científicas e tecnológicas. 1 ed.Salvador: Edufba, v. 2, p. 100-120. 2010.

APPERLEY, T.; JAYEMANE, D. A Virada Material dos Game Studies. Lumina - Revista do Programa de Pós-graduação em Comunicação. Vol.11, nº 1 , Abril 2017. Disponível em: <https://lumina.ufjf.emnuvens.com.br/lumina/article/view/721>. Acesso em 16 de abril de 2018.

BIGNOTTO, C.C. O computador e a leitura "natural". Leitura. Teoria \& Prática, v. 32, p. 3-10. 1998.

BOGOST, I. The Rhetoric of Video Games. In: SALEN, Katie (ed.). The Ecology of Games: Connecting Youth, Games and Learning. Cambridge, Massachusetts: The MIT Press, p. 117-139, 2008. Disponível em: <http://www.cogsci.rpi.edu/public_html/ruiz/EGDFall2013/readings/RhetoricVideoGames_Bogost. pdf $>$. Acesso em 16 de abril de 2018.

GRIMM, G.F.H.; CALOMENO, C. Representações Visuais: uma análise em jogos digitais educacionais. In: Congresso Brasileiro De Pesquisa E Desenvolvimento Em Design, 2010, São Paulo. 9 P\&D Design 2010, 2010.

CEASA-ES - Centrais de Abastecimento do Espírito Santo - Ceasa/ES. 2018. Disponível em: <https://ceasa.es.gov.br>. Acesso em 20 de abril de 2018.

CHANG, A.Y. Back to the Virtual Farm: Gleaning the Agriculture-Management Game. ISLE: Interdisciplinary Studies in Literature and Environment, v. 19, n. 2, p. 1-16, 2012. ISSN 1076-0962. Disponível em: <https://academic.oup.com/isle/article-pdf/19/2/237/2152636/iss007.pdf >. Acesso em 16 de abril de 2018.

CHARTIER, R. A História Cultural entre práticas e representações. Tradução Maria Manoela Galhardo. 2. ed. Portugal: Difel, 2002.

CRAWFORD, C. The Art of Computer Game Design. Washington State University, 2000. Disponível

<http://www.digitpress.com/library/books/book_art_of_computer_game_design.pdf $>$. Acesso em 08 de setembro de 2017. 
FARDO, M.L. A gamificação aplicada em ambientes de aprendizagem. Revista Novas Tecnologias na Educação, Porto Alegre, v. 11, n. 1, p. 1-9. 2013.

FILGUEIRA, F.A.R. Novo manual de olericultura: agrotecnologia moderna na produção e comercialização de hortaliças. 3. ed. rev. e ampl. Viçosa, MG: UFV, 2013. 421 p.

FALQUETO-LEMOS, A.; DALVI, M.A. Videogames, leitura e literatura: aproximações bibliográficas multi e transdisciplinares. (Con)textos Linguísticos, v. 7, pp. 6-27. 2013.

FleURY, A.; NAKANO, D.; SAKUDA, L.O. Proposição de Políticas Públicas direcionadas à Indústria Brasileira de Jogos Digitais. Pesquisa do GEDIGames, NPGT, Escola Politécnica, USP, para o BNDES, 2014a. Disponível em: <http://www.abragames.org/uploads/5/6/8/0/56805537/preposicao_de_politicas_publicas_direciona das_a_industria_brasileira_de_jogos_digitais.pdf > Acesso em 08 de setembro de 2017.

FLEURY, A. SAKUDA, L.O. CORDEIRO, J.H.D.O. I Censo da Indústria Brasileira de Jogos Digitais, com Vocabulário Técnico sobre a IBJD. Pesquisa do GEDIGames, NPGT, Escola Politécnica, USP, para o BNDES, 2014b. Disponível em: <http://www.abragames.org/uploads/5/6/8/0/56805537/i_censo_da_industria_brasileira_de_jogos_d igitais.pdf $>$ Acesso em 08 de setembro de 2017.

FRAGOSO, S.; CRUZ, M.A.; REBS, R.R.; REIS, B.M.; CAETANO, M.; SANTOS, L.; KURTZ, G.B. Tendências temáticas das trilhas do SBGames e das Teses e Dissertações sobre jogos defendidas no Brasil nos últimos 15 anos. SBC - Proceedings of SBGame, 2016. ISSN 2179-2259. Disponível em: <https://idocslide.com/tendencias-tematicas-das-trilhas-do-sbgames-e-das-teses-e-dissertacoessobre-jogos-defendidas-no-brasil-nos-ultimos-15-anos-9urVUw8> Acesso em 16 de abril de 2018.

GALEY, A.; CUNNINGHAM, R.; NELSON, B.; SIEMENS, R.; WERSTINE, P. Beyond Remediation: The Role of Textual Studies in Implementing New Knowledge Environments. In: NewTechnologies in Medieval and Renaissance Studies 3. pp. 21-48. 2011.

MELLO, S.C. Olericultura I - Hortaliças de Flores, Flores e Frutos - Departamento de Produção Vegetal - ESALQ/USP - Material de aula. Disponível em: < http://www.pointer.esalq.usp.br>. Acesso em 20 de abril de 2018.

MURRAY, J. The last word on ludology v narratology. DiGRA 'Worlds in Play' Conference, Vancouver, Canada, 2005.

PAIVA, V.L.M.O. O uso da tecnologia no ensino de línguas estrangeiras: breve retrospectiva histórica. In: $7^{\mathbf{0}}$ Encontro do CELSUL (Centro de Estudos Linguísticos do Sul), 2006, Pelotas. Santa Maria: Gráfica Editora Pallotti, 2006. p. 68-68. 
SILVA, G.A.; CASTANHO, R.B. Mapeamento da agricultura urbana no município de Ituiutaba. Horizonte Científico, vol 5, $\mathrm{n}^{\circ}$ 2, 2011.

SICART, M. The Ethics of Computer Games. The MIT Press, 2011.

TAVINOR, Grant. The Art of Videogames. Malden MA: Wiley Blackwell, 2009.

JOGOS:

Let's Farm. Playday Games, 2017.

Hay Day. Supercell, 2013.

Top Farm. MPForce, 2017.

Farm Story 2: Jogos de Fazenda. Storm8 Studios, 2017.

Township - Fazenda e Cidade. Playrix Games, 2017. 